\title{
ESTADOS COM FRONTEIRAS: \\ UM ESTUDO SOBRE A CONCEPÇÃO DE ESTADOS EUROPEUS
}

STATES WITH BORDERS: A STUDY ON THE DESIGN OF EUROPEAN STATES

\section{Damaris de Oliveira Santos ${ }^{1}$}

RECEBIDO EM: 30/11/2016 / APROVADO EM: 11/02/2017

DOI: $10.5902 / 2317175824987$

\section{RESUMO}

Este trabalho busca problematizar as concepções de estados europeus e suas fronteiras como um produto historicamente construído, bem como observar as implicações que podem surgir a partir da consolidação de tais concepções. Para tanto, são empregadas proposições de autores como Hobsbawn, Man, Barth e Montero, com o intuito de discorrer sobre a ideia de identidade nacional e identidade étnica, noções que podem fomentar barreiras à mobilidade populacional dentro de determinado território, assim como xenofobia e aversão ao "outro", especificamente dentro do contexto europeu. Com base em um estudo de natureza qualitativa e descritiva realizado a partir da revisão bibliográfica, discute-se, também, o pluriculturalismo, problematizando a noção de "construção social" sobre o Estado e as identidades nacionais ou sociais. Verificou-se, assim, que sentimentos de não aceitação ao outro podem ser fatos recorrentes no mundo moderno, de modo que uma possibilidade para refletir acerca dessa problemática seria o entendimento de que a comunidade europeia é uma construção imaginada e de que, por meio da inserção do pluriculturalismo, é possível criar projetos e ações para a inserção cada vez maior dos considerados diferentes.

Palavras-chave: Estados Nacionais Europeus; Fronteiras; Identidades nacionais; Comunidade europeia imaginada; Pluriculturalismo.

1 Graduada em Ciências Sociais pela Universidade Federal Rural do Rio de Janeiro. Atualmente mestranda do curso de Ciências Sociais e bolsista CAPES. E-mail: damaris_osantos@hotmail.com 


\begin{abstract}
This work aims problematize the European states conceptions and their frontiers as a historically builtproduct, as observe the implications may arise from the consolidation of this conceptions. Therefore, we use authors such as Hobsbawn, Man, Barth, Montero, aiming discuss the idea of national identity and ethnic identity, notions can promote barriers to populational mobility within a certain territory, as well xenophobia and aversion to the "other", specifically within the European context. Based on a study of qualitative and descriptive nature made from bibliographical review, it was also tried to discuss pluriculturalism, problematizing the idea of "social construction" on the State and national or social identities. It was verified that feelings of non-acceptance to the other can be recurrent facts in modern world, so a possibility to reflect about this problematic would be the understanding that European community is an imagined construction and, through insertion of multiculturalism, it's possible create projects and actions to increase insertion of those considered different.
\end{abstract}

Keywords: European National States. Borders. National identities. Imagined European community. Pluriculturalism;

\title{
1 Introdução
}

Um dos grandes dilemas que marcam o início do século $X X$ são os problemas relativos ao terrorismo e à imigração. Esses dois processos podem apresentar uma relação simétrica, no sentido de que as imigrações de refugiados para a Europa são, muitas vezes, barradas devido à preocupação dos países europeus deque, entre os "refugiados", existam grupos extremistas. Geralmente, os refugiados são oriundos de países em guerra civil.

Dois casos específicos revelam a problemática em questão. $O$ ano de 2016, por exemplo, inicia com imagens que sensibilizam o mundo- trata-se do caso do menino sírio morto por afogamento e encontrado na Turquia, pertencente a um contexto em que, segundo o jornal o Globo (2015), os refugiados fogem de guerras, perseguições religiosas, extremistas, miserabilidade etc. Ainda a esse respeito, podem-se citar os casos de ataques terroristas ocorridos em março do mesmo ano em Bruxelas na estação de metrô Maelbeek e no aeroporto internacional de Zaventem, vitimando 34 mortos e 200 feridos. O grupo responsável pelos ataques faz parte, conforme o Globo (2016), do Estado Islâmico. Em uma reportagem publicada nesse mesmo jornal, é apresentado o pronunciamento do rei Philippe, da Bélgica (Globo, 2016): “[...] Diante da ameaça, continuaremos a responder juntos com firmeza, calma e dignidade [...]". Esse argumento possibilita pensar acerca do fato de que, muitas vezes, os ataques terroristas são utilizados como justificativa para o impedimento da entrada de imigrantes em alguns países, como é o caso da Hungria, por exemplo, que construiu uma barreira de arame (extensão de $175 \mathrm{~km}$ ) na fronteira com a Sérvia. Esses acontecimentos acabam permitindo que sentimentos nacionais nos países europeus, como oposição e preconceito 
aos imigrantes (xenofobismo), sejam fortalecidos. Diante desse contexto, é interessante pensar sobre a forma como a concepção desses Estados europeus é construída historicamente.

\section{Referencial teórico}

O objetivo deste trabalho é analisar as concepções de Estados europeus, partindo do pressuposto de que são construtos sociais e observando as implicações dessas ideias na sociedade. Nesse sentido, a análise aqui proposta sobre a formação dos estados europeus e da "comunidade imaginada europeia" tem como ponto de partida a visão de Mann (2000), para quem os países não se constituíram de forma isolada. A construção da identidade nacional ocorre a partir de um fato histórico e construído, paralelamente à identidade europeia, marcada por ser branca, crista e ocidental. Mann (2000) entende que essa identidade gera uma aversão aos imigrantes que não são considerados como iguais e que os interesses de mercado acabam impedindo uma maior união entre a comunidade em termos culturais, sociais e de direitos democráticos. As barreiras físicas (negação da entrada de imigrantes) e morais (exclusão de direitos) que separam o "outro" impedem a construção de uma comunidade europeia imaginada nos âmbitos de um pluralismo cada vez mais radical. Como aborda Mann (2000), o conceito de Estados deve ser amplo, assim como a noção de comunidade imaginada europeia deve ser reinventada.

Hobsbawn (2008) alerta sobre o modo como os estados europeus criaram a ideia de "nação", servindo-se dela para disputas internacionais. MayburyLewis (2003), por sua vez, denomina-os empresários "étnicos", já que criaram as diferenças étnicas por interesses escusos. Hobsbawn (2008) aponta como, no contexto em que fortes preconceitos aos "não iguais" podem ser verificados, produz-se cada vez mais a xenofobia, o que pode levar a adesão de "alguns" indivíduos ao fundamentalismo, processo que abarca um projeto bem definido de vida para seus adeptos (geralmente ligado a princípios religiosos). Assim, importa ressaltar que Maybury-Lewis propõe como solução a esse cenário o pluriculturalismo, "modelo" de "Estado-Nacional" que Hobsbawn acredita que não duraria para sempre.

Para Maybury-Lewis (2003), o Estado cria fronteiras, mas também pode ser um local de aceitação das diferenças, devido à possibilidade, conforme Wolf (2003), de entidades juntarem-se e misturem-se dentro de uma aglomeração de diferenças (fronteira). Nesse sentido, Marybury-Lewis (2003) afirma que - Estado pluricultural é o ideal para a construção dessas convivências. Um exemplo desse Estado é o caso brasileiro, que, como propõe Seyferth (2000), passou por um longo processo dramático e conflituoso até sua consolidação.

Na concepção de Montero (2012), o pluriculturalismo traria em seu cerne a assimilação das diferenças e a concessão de alguns direitos coletivos. Nesse contexto, de acordo com Pinto (1999), apesar de o discurso sobre intolerância 
nunca ter sido tão amplamente difundido, não se verificam resultados mais efetivos. Diante disso, Pinto (1999) propõe como solução um significante vazio para o conceito de universal, o que implicaria a ressignificação da própria noção de tolerância e uma concepção de pluralismo por direitos plenos. Em termos hobsbawnsianos, os estados europeus são uma criação imaginada que acaba resultando em ações práticas no mundo em que vivemos, criando fronteiras físicas e mentais, que também são imaginadas, ou seja, são criadas, sem ter um papel apenas de exclusão, mas também de um lugar de encontro nos parâmetros de Wolf (2003).

\section{Método de pesquisa}

A metodologia utilizada foi a pesquisa qualitativa a partir de revisão bibliográfica pautada em autores teóricos que discutem a concepção do Estado, tais como Mann (2000), Hobsbawn (2008) e Maybury-Lewis (2003), bem como de análise das notícias em jornais, como o Globo, no período de 2015 a 2016. As matérias retratavam as perseguições que sofrem os imigrantes e as ações dos Estados europeus na tentativa de impedir o acesso destes em seus países.

\section{Apresentação e discussão dos resultados}

\subsection{As concepções de estados nacionais europeus}

Segundo Mann (2000), alguns autores afirmam que o Estado Nacional Soberano Moderno estaria se fragmentando na Europa e levando a um fim desse sistema. Mann (2000, p. 313) coloca que, a partir do século XVIII, a Europa passa a ter o domínio da força militar e que a ideia de soberania estatal na Europa está relacionada com esse poder legítimo da força. Os estados nacionais ajudaram na consolidação das sociedades civis, as quais se mobilizam e fazem força também frente ao Estado.

Para Mann (2000), o processo de formação dos estados europeus ocorreu no início do século XX, no pós-guerra (Segunda Guerra Mundial), quando praticamente todos os territórios da África e Ásia foram divididos em países, mantendo vínculos de dependência econômica com suas antigas metrópoles.

Mann (2000) afirma, ainda, que a ideia de que os estados nacionais soberanos terminaram é superficial, já que estes ainda estão amadurecendo e que as relações entre os países nunca foram só nacionais, mas também transnacionais e geopolíticas. A partir de uma identidade social da dita sociedade civil, caracterizada por ser cristã, ocidental e branca, é construída a oposição com o "resto do mundo", discriminando outros povos.

Alguns aspectos específicos sobre o contexto europeu são relatados por Mann (2000), como o tratado de Maastricht, que ocasionaria a perda da soberania 
dos países participantes como Alemanha Ocidental, Bélgica, Luxemburgo, França e Países Baixos. Esse tratado regula as relações de mercado, econômicas e políticas e estabelece padronização das mercadorias. Segundo Mann (2000), o trabalho passa a ser visto como mercadoria devido à exigência de especialização, o que é de certa forma preocupante, tendo em vista que a Comunidade Europeia possibilita um mercado único, com livre circulação de pessoas, mercadorias e serviços, em que não há comprometimento com questões sociais nem um ambiente comum de defesa militar. Isso gera descrença na soberania e impossibilidade de um estado único europeu - e menos ainda da formação de um estado federal, uma vez que as ideias de bem-estar social e controle de "vigilância" sobre seu território não ocorrem na Comunidade Europeia.

A pergunta central para Mann (2000) é: podem as instituições da Comunidade Europeia ser mais democráticas que burocráticas? Segundo Mann (2000), a resposta é não, porque as instituições democráticas surgiram a partir dos estados nacionais. A justificativa para isso é que, em um Estado de garantias aos seus cidadãos, o bem-estar social não pode se estabelecer na Comunidade Europeia, uma vez que a lógica dessa Comunidade seria justamente voltada para o lucro do mercado e para a transformação da Europa em um bloco econômico capaz de fazer frente à maior potência mundial, os Estados Unidos. Pode-se verificar essa impossibilidade também pelo fato de que os países com economias mais fragilizadas e participantes da atual União Europeia são os primeiros a sofrerem fortes ameaças de serem expulsos do bloco caso não paguem suas dívidas. Um exemplo é a tensão envolvendo a Alemanha e a Grécia, em que a Alemanha exige que o governo adote medidas intervencionistas e corte os gastos com benefícios sociais. A resposta dada pela Grécia em 2015 foi negar o acordo, argumentando que, se fosse assim, a Alemanha deveria "pagar" as dívidas que possui até hoje oriundas da Segunda Guerra Mundial. A partir disso, é possível perceber como a antiga Comunidade Europeia e a atual União Europeia ainda mantêm sua lógica centralizada no mercado (GLOBO, 2015).

De acordo com Mann (2000), a maior transformação na Europa do século XX foi a perda do autoritarismo de esquerda e direita, passando a ser dominante o poder conservador de centro-direita, de democratas-cristãos e de socialdemocratas centristas que têm um racismo centrado na imigração. A xenofobia contra imigrantes intensificou-se no início do século XXI, fazendo com que a crença no nacionalismo fosse fortificada e que o sentimento de ódio contra o estrangeiro criasse barreiras para uma unificação europeia mais intensiva em aspectos culturais, sociais e políticos (em condições de direito). Como mencionado, os ataques à Bélgica no ano de 2016 intensificaram esse sentimento nacional e auxiliaram a tornar a liberação à imigração na Europa cada vez mais fechada.

Diante disso, conforme expõe Barth (2000), alguns grupos étnicos escolhem características e traços que são usados como demarcadores das diferenças em relação a um outro. Barth (2000) afirma, ainda, que essa identidade dos grupos pode ser mudada ao longo das transformações 
sociais, já que a fronteira não atua apenas como um ambiente que isola duas localidades, mas também como um meio de troca cultural, uma ponte para a diversidade. Nesse sentido, essa fronteira que não é limitada pode ser comparada ao pluralismo de Hobsbawn (2008). Enquanto este observa as disparidades entre os grupos étnicos e o conflito dentro dos estados nacionais, Barth (2000) analisa essas disparidades étnicas na sociedade. Essa diferença de perspectiva fica bem explicita quando Barth (2000) afirma:

[...] Assim, a persistência de grupos étnicos em contato implica não apenas a existência de critérios e sinais de identificação, mas também uma estruturação das interações que permita a persistência de diferenças culturais [...]. (Barth, 2000, p. 35)

Mann (2000) aponta que alguns autores previram o fim do estado nacional, uma vez que este se estabeleceu inicialmente pelo uso da força e que recentemente ocorreu o seu desarmamento. Mann (2000) conclui, entretanto, que o transnacionalismo do capital e da cultura não minam os estados soberanos e que essas novas concepções de estado devem se preocupar inclusive coma difusão de preconceitos e teorias racistas que só levam à intolerância e prejudicam as relações sociais, econômicas e políticas. Além disso, cabe citar a preocupação de Mann de que o socialismo deve assumir uma postura democrática e ocidental para sobreviver, frente ao capitalismo que reduz direitos e "poderes de cidadania social". Esse aspecto democrático, cada vez mais, está ameaçado diante de um mercado internacional em que seus membros são extremamente dependentes uns dos outros e que sempre prioriza a maximização dos lucros econômicos em detrimento dos interesses sociais.

Outro autor que observa essa prática "preconceituosa" apontada por Mann (2000) é Hobsbawn (2008), para quem o Estado é denominado como "uma comunidade imaginada", que cria uma dualidade entre "nós" e os "outros", criando igualmente os "amigos" e "inimigos" desse Estado. Hobsbawn (2008) coloca que essa nação foi construída ao longo da história acionando elementos culturais ou políticos para a consumação da ideia que se tem hoje. Ademais, faz uma crítica a Mann, que afirma que as economias frágeis estariam passando pelo processo de construção desses Estados aos moldes europeus. Hobsbawn (2008), na verdade, acredita que esses Estados Nacionais dificilmente se manterão.

Hobsbawn (2008), em sua análise, mostra como a construção dos Estados Nacionais é um processo datado, que perpassa toda a histórica ocidental, e que os próprios Estados construíram esse ideal de nação. Esses Estados Nacionais centralizados delimitados em um território por vezes ocasionam a xenofobia.

A xenofobia aguda ou a reação racista da população nativa de países ou regiões que recebem os influxos maciços de "estranhos" têm sido, infelizmente, familiares nos Estados Unidos, desde 1890, e na Europa ocidental, desde 1950. Se bem que xenofobia 
e racismo sejam sintomas, e não remédios. As comunidades e grupos étnicos nas sociedades modernas estão destinados a coexistir, qualquer que seja a retórica que sonhe com uma volta a uma nação sem misturas. $O$ assassinato e a expulsão em massa ("repatriação") na verdade simplificaram drasticamente o mapa étnico da Europa, e poderiam ser tentados em algumas outras regiões. Contudo, o movimento dos povos restaurou, desde então, a complexidade étnica, a qual o barbarismo buscou eliminar. Apenas hoje a típica "minoria nacional", em grande parte dos países que recebem imigrantes, é um arquipélago de pequenas ilhas mais do que uma terra maciça coerente (HOBSBAWN, 2008, p.185).

Os grupos étnicos dentro de um Estado-Nação vão lutar por seus interesses. Maybury-Lewis (2003) menciona que muitos empresários "étnicos" criam essas diferenças para se "beneficiarem" em cima das disputas, indo ao encontro da afirmação de Hobsbawn (2008) de que existem os criadores de nações para manterem disputas nos contextos internacionais. Por outro lado, essas diferenças podem servir no meio político de disputas para reivindicar autonomia de minorias. Segundo Maybury-Lewis (2003, p.14): “Etnicidade não é, então, uma condição estável, senão uma relação negociada entre um grupo e outros e entre estes grupos e o estado [...]".

Para Hobsbawn (2000), o que leva à xenofobia no contexto europeu não são simplesmente questões econômicas e financeiras - a ameaça estrangeira não ocorre por meio do desemprego em massa e da insegurança. Na década de 1970, a Europa Ocidental passou por uma forte crise, seguida de uma crise na Europa Oriental no final de 1980. Nesse contexto, surgiram movimentos como skinheads e similares, embora esses fatos sejam insuficientes para explicar a discriminação e a xenofobia.

Características físicas ou a utilização de uma língua, por exemplo, também poderiam ser usadas para definir os "outros". Hobsbawn (2000), contudo, acredita que isso não corresponde à realidade, uma vez que os estrangeiros podem "assimilar" essas características, tornando-se "comuns". Os países europeus receberam no passado inúmeros imigrantes, incentivando esse processo, e as pessoas que foram para lá assimilaram bem a cultura local.

Para o autor, a xenofobia está se tornando uma ideologia devido à crise dos valores humanos, de modo que os estrangeiros jamais poderão fazer parte da nação a qual pertencemos, HOBSBAWN (2000, p.2 81): “[...] A força da xenofobia é o medo do desconhecido das trevas em que podemos cair quando desaparecem os marcos que parecem proporcionar uma delimitação objetiva, permanente e positiva do nosso pertencimento a comunidade [...]".

O fundamentalismo pode aparecer nesses contextos de presença exacerbada das supostas diferenças, sendo um fenômeno com múltiplas causas, que pode ou não reivindicar um Estado Nacional (território) para si. Hobsbawn (2008) entende que esse projeto pode unir diferentes pessoas e conquistar muitos adeptos, como no caso dos atentados praticados por extremistas 
fundamentalistas em vários locais, a exemplo de Paris (2015) e da Bélgica (2016). O que muitas vezes causa polêmicas é que esses extremistas fundamentalistas são considerados "europeus", diante do que se pode problematizar até que ponto os europeus permitem direitos de fato a esses "adeptos aos movimentos extremistas", para que sejam considerados efetivamente nacionais.

[...] Diversamente, enquanto o fundamentalismo, com seu apelo atual, estreito e sectário, retira sua energia da demanda pela verdade universal teoricamente aplicável a todos, o nacionalismo, por definição, exclui de seu campo de ação todos aqueles que não pertencem à sua própria "nação", ou seja, a ampla maioria da raça humana. Além do mais, enquanto o fundamentalismo pode, ao menos até um certo grau, apelar para o que resta de hábitos autênticos e de tradição, ou de práticas do passado que foram incorporadas às práticas religiosas, o nacionalismo em si mesmo, como já vimos, ou é hostil para com os reais caminhos do passado, ou emerge de suas ruínas (HOBSBAWN, 2008, p. 201).

Segundo Hobsbawn (2008), existe uma diferença crucial entre o xenofobismo e o fundamentalismo, pois o fundamentalismo busca um projeto específico e minucioso para a sociedade e os indivíduos que dela fazem parte, com regras rígidas e baseadas nas suas interpretações religiosas. Hobsbawn (2008, p. 215) acredita na desconstrução desses Estados: "não é impossível que o nacionalismo irá declinar com o declínio do Estado-Nação, sem o que 'ser' inglês, ou irlandês... uma combinação desses todos, é somente um dos modos pelos quais as pessoas descrevem suas identidades, entre muitas outras que elas usam para tal". Uma proposta a essa intolerância apontada seria o pluriculturalismo:

[...] Ele pressupõe uma tolerância para culturas diversas e uma suspensão inicial de julgamento para com outras culturas, para poder entendê-las melhor e, finalmente, para poder fazer julgamentos melhores. O pluriculturalismo sério depende de um esforço tremendo para entender a diversidade cultural tanto do país no qual vivemos como no mundo em que vivemos (MAYBURY-LEWIS, 2003, p.17).

É preciso pontuar críticas feitas ao conceito de pluriculturalismo e de intolerância. O primeiro conceito preconizaria uma convivência pacífica em relação às diferenças, mas é criticado por sua proposta de ações efetivas de combate. Paula Montero (2012) faz a análise da diferença entre o multiculturalismo e esse pluriculturalismo, indicando que o multiculturalismo preconizaria as reivindicações políticas das diferenças, pretendendo mantê-las para a luta nos espaços públicos. Para Montero (ARRUDA, 2005 apud MONTERO, 2012, p.89): “[...] O pluriculturalismo significa aqui o reconhecimento do direito a diferença cultural e estipula alguns direitos coletivos tais como o direito ao território tradicional [...]". Para Montero (2012, p.90): "[...] pluralismo busca 
assegurar o nível de assimilação necessário para promover a integração, enquanto o multiculturalismo encontra virtudes políticas na própria produção das diferenças". Esse confronto marca a problemática em torno da noção de universalidade e da questão das disputas por direitos, levando a uma ideia de "assimilação" da diversidade cultural. O objetivo aqui não é discutir a concepção do multiculturalismo, mas destacar a existência de críticas a essa corrente e lembrar que os conceitos de pluralismo e multiculturalismo são utilizados por vários autores com significados diferentes - neste estudo, adota-se o conceito de pluriculturalismo proposto por Maybury-Lewis (2003), que visa à disputa por efetivo direito no âmbito do poder político.

Pinto (1999) estabelece uma crítica ao significado do termo tolerância, afirmando que este faz referência a uma relação de poder, que acaba levando a uma oposição entre aqueles que são considerados normais ou não. Construiuse na história um discurso de aceitação das diferenças, mas nunca houve tantos casos de violência contra esses "outros" (com a miséria e exclusão). A questão da universalidade é posta também em pauta quando afirma que não é sinônimo de garantia da tolerância às diferenças; muito pelo contrário, já que sua prioridade é com as classes dominantes. Um efeito dominó também leva a um desequilíbrio no contexto de grandes disputas por direitos, em que a maior fragmentação das identidades gera a desarticulação nos combates, já que se perde uma voz que faria mais frente ao poder central. A solução apontada pela autora é a noção de universal como "significante vazio": dar novos significados ao universal, que aceitaria as diferenças particulares mais radicais. Afirma, ainda, que muitos defensores do multiculturalismo esquecem que foram os dominantes que construíram muitas identidades conhecidas como "negros, mulheres, índios..." e que essas categorias são vinculadas a fatores como cor, sexo, posição e espaço geográfico que ocupa, existindo uma tentativa de atribuir a essas identidades um status de positividade. Pinto explicita que, mesmo sendo positiva essa tentativa de qualificação das identidades, ao mesmo tempo ela pode fragmentar, isolar e ser um mecanismo das condições de opressão, acentuando as diferenças de um ponto de vista negativo.

Diante disso, Pinto (1999, p. 18) afirma: "[...] a inclusão não é a eliminação da diferença, mas o reconhecimento da diferença; a exclusão, esta sim, é o não reconhecimento do outro [...]". Para ela, não se trata de tolerar só uma atitude que consideremos favorável ou não, mas permitir a "inclusão democrática da diferença". Sempre haverá um combate entre essas identidades, em função do que Pinto indaga se não seria melhor superar essas "diferenças", já que as identidades que são colocadas para as minorias levam a lugares de segregação e pauperização. Nesse sentido, a proposta de Pinto (1999) seria redistribuir os poderes na sociedade para que os "tolerados" não dependam da tolerância dos dominadores. Essa discussão dos conceitos é muito importante porque não existem garantias da superação nem da manutenção dessas diferenças. Somos um tanto céticos em relação a essa superação das identidades, uma vez que construímos nosso "eu" a partir de estruturas de oposições. Também não acreditamos na 
plena manutenção dessas identidades, já que elas são construídas e disputadas em determinados contextos. Preferimos acreditar em uma ressignificação também da tolerância que incorpora a noção de "reconhecimento" das diferenças e de um pluralismo que emerge das lutas nos espaços públicos.

\subsection{Uma possibilidade de conviver com as diferenças: Estado pluralista}

Adotamos neste trabalho a noção do pluriculturalismo defendido por Maybury-Lewis (2003). Podemos pensar o Estado como uma fronteira que não só separa e limita outros países, mas também cria fronteiras étnicas dentro de si mesmo, permitindo a existência dessas diferenças étnicas. Outro autor que permite pensar a fronteira como um lugar de encontro é Wolf (2003), quando coloca que as entidades se juntam:

[...] Sabemos também que tais entidades sempre existiram na presença de outras etnias, povos, nações; que elas se misturam e se fundem com outras, tanto biológica quanto culturalmente; e que, portanto, entidades sociais e culturais e identidades não são dadas, mas construídas no próprio turbilhão das mudanças (WOLF, 2003, p. 244-245).

Esse encontro na "fronteira" só é possível em um Estado que aceita ser pluriétnico e pluricultural, promovendo paz, estabilidade e tranquilidade. Maybury-Lewis (2003) critica conservadores americanos que afirmam que o pluriculturalismo tira a unidade da nação.

Um exemplo do que Maybury-Lewis propõe é o Estado Nacional do Brasil, que, a partir da Constituição de 1988, assume-se como um Estado Pluralista, fundado pelo ideal de harmonia e preocupado com a ordem nacional e internacional. Por outro lado, Seyferth (2000) mostra como o nacionalismo brasileiro passa por fortes crises por não aceitar essas diferenças ao longo da história (SEYFERTH, 2000, p.107): “[...] As preocupações com a unidade cultural, racial e territorial da nação... redundaram num processo forçado de nacionalização que considerou ilegítimas as diferenças étnico-culturais [...]".

No início deste estudo, pontuamos a proposição de Mann (2000) de que a União Europeia não destrói a noção de Estado, mas constrói um novo significado. Esse Estado também cria barreiras aos indivíduos que não pertençam à nação europeia. Contudo, devido a tantos problemas relacionados a essas fronteiras de separação, a União Europeia passa a adotar medidas que visem dirimir esses conflitos. Um exemplo disso poderia ser o Programa de mobilidade Erasmus², um projeto da comunidade europeia que visa promover o incentivo à educação entre jovens.

$\overline{20}$ projeto permite que estudantes façam intercâmbio em contato com diferentes culturas e aperfeiçoem seu conhecimento em suas áreas de estudo. Também viabiliza o aprendizado e o aperfeiçoamento do contato com uma língua estrangeira, além de criar a possibilidade de fazer estágios. Estudantes de graduação, mestrado e doutorado oriundos de diferentes países europeus podem estudar em toda a União Europeia. O período de duração varia de três meses a um ano. O estudante pode conseguir bolsa de estudo para o intercâmbio ou estágio. Essa é uma das várias iniciativas educacionais e de apoio a diferentes pessoas dentro da Comunidade Europeia. Financiado pela União Europeia, com um orçamento de 14,7 bilhões de euros, 0 projeto visa alcançar em torno de quatro milhões de europeus até 2020. 


\section{Considerações finais}

Podemos perceber como a construção do Estado Nacional passa por uma concepção histórica que está carregada de amplos sentidos e lutas. Diferentes autores trabalham a questão desse Estado que procura padronizar uma identidade nacional, fazendo com que diferentes grupos étnicos sofram limitações de fronteiras (seja internamente ou externamente). Quando essa concepção de Estado Nacional é criada e se torna um fato objetivo no imaginário da população, opõe-se a uma outra que também é construída. No caso europeu, tenta-se limitar cada vez mais o fluxo de pessoas, especialmente das oriundas do contexto asiático e africano. A justificativa para essa "limitação" ou "exclusão" baseia-se em uma proteção à ameaça de "ataques terroristas" advindos atualmente de um Estado que faz oposição ao suposto "Estado Nacional democrático", o Estado Fundamentalista Islâmico. Com isso, nega-se refúgio a pessoas que tenham alguma ligação próxima com essas localizações geográficas. Sustentamos, contudo, que essa explicação não é suficiente e que, muitas vezes, essas pessoas são rejeitadas por um xenofobismo ao estrangeiro, que não pode ser um igual.

Por outro lado, toda a discussão feita até aqui demonstrou que essas diferenças étnicas e culturais são apenas resultantes de criações humanas e que não se sustentam. Como mostra Barth (2000), também as fronteiras podem ser um local de construção de trocas, e é por isso que trouxemos essa visão da fronteira não como demarcadora de limites (marcadores de diferenças e entrada de pessoas), mas como um local de possibilidade para a construção de novos significados. As fronteiras criadas pelos Estados Nacionais não conseguem se sustentar por muito tempo; cada vez mais os Estados-Nação precisam construir diferenças, para impedir que o intercâmbio de pessoas e valores não torne o mundo totalmente "conectado". Costa (2013) demonstra que essa fronteira na cidade de Corumbá (Brasil e Bolívia) é acionada algumas vezes pelo Estado, colocando o outro (no caso os bolivianos) como índios, atrasados e sujos, que transmitem doenças. Costa (2013) afirma, ainda, que não se pode reduzir uma explicação de visão centralizadora do Estado sobre determinado território e população, bem como não se pode ignorar totalmente a influência que em certa medida o Estado exerce sobre os direitos concedidos àqueles que são considerados seus cidadãos. A visão de fronteira apresentada por Costa (2013) é pertinente ao defendido neste estudo:

Essa divisão absoluta entre nós e eles não se sustenta quando analisamos de forma empírica a vida fronteiriça, mais rica e complexa em função dos processos de "hibridização", de aquisição de dupla nacionalidade e demais direitos de cidadania nos dois lados, além dos fluxos culturais e identitários que aí ocorrem. [...] (COSTA, 2013, p.153). 
O efeito reverso também acontece: essas diferenças específicas culturais valorizadas são mantidas justamente pela convivência com essas diferenças. A ideia aqui é pensar sobre a possibilidade de esse Estado pluralista permitir a quebra de "fronteiras", não para se tornar uma unidade cultural, mas para possibilitar o intercâmbio e fluxo de valores. Não se trata de passar valores de "uns" aos "outros" simplesmente, mas de conviver e valorizar todos os tipos de "fronteiras e diferenças culturais".

Como mencionado, uma das formas de o Estado promover esse aprendizado "pluricultural", no contexto da Comunidade Europeia, pode ser com o Programa de mobilidade Erasmus, em que diversos estudantes e profissionais podem estudar em outros contextos e ter essa experiência de convivência com as diferenças. Assim, essa ideia pode se expandir também para uma noção mais ampla de mundo, em que as fronteiras não apenas separam, mas também ligam diferentes pessoas e nações. Gostaríamos, ainda, de salientar a existência de uma diferença gerada pelas nações que, no contexto internacional, apresentam-se como uma unidade cultural em oposição a outra. Além disso, as diferenças étnicas dentro de uma cultura podem promover também, internamente ou externamente, a crise das identidades e respeito às diferentes "gentes". Queremos com este trabalho dar novo significado à fronteira estatal, cultural e étnica, nomeando "fronteira" todo intercâmbio que promove a tolerância e trocas multilaterais de produtos e ideias. Assim, fronteira é entendida aqui no sentido de permitir o intercâmbio de "vida" ${ }^{3}$, e não de "morte".

Sonhamos em construir um diálogo comum entre as pessoas de diferentes partes do mundo, por meio do intercâmbio não só de produtos, mas também de uma consciência mais coletiva e integrada de pertencimento a uma comunidade mundial. É possível transpor as fronteiras físicas e ideológicas, de modo a, se não as erradicar, ao menos questioná-las e repensá-las para a construção de única "fronteira" que possibilite o encontro e a convivência permanente entre os "outros" e o "nós".

3 Vida no sentido tanto de pessoas quanto de valores, pois os preconceitos adoecem e levam à morte de novas ideias. 


\section{Bibliografia:}

BARTH, F. Os grupos étnicos e suas fronteiras. In: LASK, T. (Org.). O guru, o iniciador e outras variações antropológicas. Rio de Janeiro: Contracapa, 2000.

BRASIL. Constituição da República Federativa do Brasil de 1998. Preâmbulo. Planalto. Disponível em<http://www.planalto. gov.br/ccivil_03/Constituicao/Constituicao.htm> Acesso em 15 de Abril de 2016 às 16h00min.

DA COSTA, Gustavo Villela Lima. O muro invisível: a nacionalidade como discurso reificado na fronteira BrasilBolívia. Tempo Social, v. 25, n. 2, p. 141-156, 2013. Disponível em: <http://www.revistas.usp.br/ts/article/ view/78769/82821>. Acesso em: 30/07/2016.

SOBRE O ERASMUS +. ERASMUS. Disponível em: <http://ec.europa.eu/programmes/erasmus-plus/discover/index_pt.htm>. Acesso em: 03 de Abril de 2016 as 14h00min

OPPORTUNITIES FOR INDIVIDUALS. ERASMUS. Disponível em <http://ec.europa.eu/programmes/erasmus-plus/individuals_ en\#tab-1-1>. Acesso em 04 de Abril de 2016 às 10h30min.

VIDEO GALLERY. ERASMUS. Disponível em <http://ec.europa.eu/programmes/erasmus-plus/video/erasmus-plus-youthexchanges>. Acesso em 04 de Abril de 2016 às 11h32min

RUFFATO, Luiz. Imigração e Xenofobia: Brasil, país de diversidade, acompanha horrorizado as manifestações de xenofobia contra os médicos cubanos, senegaleses e haitianos. El pais. 09/09/2015. Disponível em: <http://brasil.elpais. com/brasil/2015/09/09/opinion/1441811691_233922.html>Acesso em 17 de março de 2016 às 20h25min.

FOTO CHOCANTE DE MENINO MORTO REVELA CRUELDADE DE CRISE MIGRATÓRIA. Globo. São Paulo 02/09/2015. Disponível em <http://g1.globo.com/mundo/noticia/2015/09/foto-chocante-de-menino-morto-vira-simbolo-dacrise-migratoria-europeia.html>. Acesso em 25 de Março de 2016 às 18h50min

ATAQUES TERRORISTAS NA BÉLGICA DEIXAM DEZENAS DE MORTOS E FERIDOS. São Paulo: 22/03/2016. GLOBO. Disponível em <http://g1.globo.com/mundo/noticia/2016/03/aeroporto-de-bruxela-na-belgica-registraexplosoes.html 25/03/2016>. Acesso em 25 de Março de 2016 às 18:50

GRÉCIA QUANTIFICA DIVIDIDA DE GUERRA ALEMÃ: 279 bi (07/04/2016). GLOBO. Disponível em <http://oglobo.globo. com/economia/grecia-quantifica-divida-de-guerra-alema-279-bi-15800342>. Acesso em 17 de Março de 2016 às $19: 45$

HOBSBAWN, Eric. Nações e Nacionalismo desde 1780. Rio de Janeiro: Paz e Terra, 2008. Introdução e Capítulos I, IV, V $\mathrm{E} \mathrm{VI.}$

HOBSBAWN, Eric. Etnia e nacionalismo na Europa de hoje. In: BALAKRISHNAN, G. (Org.): Um mapa da questão nacional. Rio de Janeiro: Contraponto, 2000.

MANN, Michael. Estados nacionais na Europa e noutros continentes: diversificar, desenvolver, não morrer. In: BALAKRISHNAN, Gopal. (org.) Um mapa da questão nacional. Rio de Janeiro: Contraponto, 2000.

HALL, Stuart. Quando foi o pós colonial? In: Hall, Stuart. Da Diáspora. Belo Horizonte: UFMG, 2003.

MAYBURY-Lewis, David. Identidade Étnica em Estados Pluriculturais. In: ZARUR, George e SCOTT, Parry (orgs). Identidade, Fragmentação e Diversidade na América Latina. Recife: Editora Universitária UFPE, 2003.

MONTERO, Paula. Multiculturalismo, identidades discursivas e espaço público. Revista de Sociologia e Antropologia, v.2, n.4, p.81-101, 2012.

PINTO, Célir. Jardim. A democracia desafiada: presença dos direitos multiculturais. Porto Alegre: UFRGS, 1999.

SEYFERTH, G. Identidade Nacional, diferenças regionais, integração étnica e a questão imigratória no Brasil. In: Zarur, G. de C. Leite. (Org.). Região e Tradição na América Latina. 1 ed. Brasília: Ed. UnB, 2000

WEBER, Max. Classe, estamento, partido. In: GERTH; MILLS (org.). Ensaios de sociologia. Rio de Janeiro: Zahar Editores, 1963, p. 211-228

WEBER, Max. "Conceitos sociológicos fundamentais" e "tipos de dominação" In Economia e Sociedade. Brasília, Ed. da UNB.

WOLF, Eric. R. Etnicidade e nacionalidade. In: FELDMAN-BIANCO, Bela e RIBEIRO, Gustavo Lins (orgs). Antropologia e Poder, Brasília/Campinas, UNB/Unicamp, 2003. 